\title{
Quantification and Context in Measure Adverbs*
}

\author{
Ashwini Deo \\ Yale University
}

\author{
Maria Piñango \\ Yale University
}

\begin{abstract}
We present a universal quantifier analysis of for-adverbs which builds on the notion of context-determined temporal partitions (Deo 2009) and intermediate distributivity (Schwarzschild 1996; Champollion 2010a, b). In contrast to the measure function analysis, this analysis places neither selectional restrictions on the arguments of for-adverbs, nor does it appeal to type-shifting coercion operators in accounting for iterative and imperfective readings associated with them. The proposal improves on earlier quantificational analyses in dealing with the minimal parts problem and the scopal restriction problem. Further, it also succeeds in capturing a robust psycholinguistic pattern of delayed and sustained cost associated with comprehension of for-adverbs composed with semelfactive/telic predicates, which until now had not been satisfactorily understood. It does so by attributing the cost, not to a mismatch-repair mechanism, but to the lexical and contextual mining necessitated in the retrieval of contextual information (a partition measure) without which the expression cannot be fully interpreted.
\end{abstract}

Keywords: aspect, coercion, contextual restriction, for-adverbs, quantification, type-shifting, psycholinguistics

\section{Introduction}

This inquiry begins with the widely held assumption that for-adverbs denote measure functions that come with a selectional restriction: their domain of application is restricted to atelic, durative predicates. This assumption captures the acceptability contrast in (1) as one involving the violation of selectional requirements.

(1) a. Mary walked for ten minutes.

b. ?? Mary found her cat for ten minutes.

But it is at least as well-noted an observation that for-adverbs often do combine successfully with telic (2) and punctual (3) predicates. On the selectional restriction assumption, this apparent compatibility between for-adverbs and telic/punctual

* Many thanks to Pranav Anand, Lucas Champollion, Angelika Kratzer, Zoltan Szabo, Eytan Zweig, SALT reviewers, and the SALT XXI audience for comments and discussion about this work. All errors are ours alone.

C2011 Deo \& Piñango 
predicates is analyzed as resulting from some reinterpretative mechanism, called coercion, which coerces an atelic interpretation upon a telic predicate (Moens and Steedman 1988, Pustejovsky 1995, Jackendoff 1997, de Swart 1998).

For instance, the telic predicates in $(2 \mathrm{a})$ can be coerced into their imperfective counterparts. The sentences thereby convey that an event of the type denoted by the basic predicate was ongoing for the duration of an hour. Similarly, the predicates in (2b) can be coercively interpreted as iterative predicates, conveying that there were repeated events of the type denoted by the basic predicate over the duration of two months (Krifka 1998).

a. Mary read a book/built a sandcastle/baked a cake for an hour.

b. Mary played a sonata/walked a mile/biked to the store for two months.

In the case of semelfactives, (e.g. sneeze, jump), a class of punctual, atelic predicates (Smith 1991), composition with for-adverbs is always acceptable and obligatorily gives rise to an iterative interpretation. This iterative interpretation has also been attributed to a coercive process/mechanism that maps punctual predicates to their iterative counterparts (Moens and Steedman 1988, Pustejovsky 1995, Jackendoff 1997, de Swart 1998).

a. John sneezed for an hour.

b. Peter jumped for an hour.

This coercion-based explanation of the patterns of distribution and interpretation of for-adverbs in combination with distinct predicate properties relies on two things: (a) the assumption of a mismatch between for-adverbs and some of their arguments; and (b) the availability of a resolution in the form of a semantic shift in the meaning of predicates (to their iterative or imperfective versions). This is a specific instance of the more general aspectual coercion hypothesis given in (4):

Aspectual Coercion Hypothesis: Mismatches between aspectual restrictions on functors and aspectual properties of their arguments are resolved by the introduction of reinterpretation mechanisms that type-coerce the arguments into the desired aspectual type.

This sort of analysis has drawn much interest and attention from neuro- and psycholinguistics for two reasons. First, the presence of atelic, durative interpretations (iterative or imperfective) without any overt morpho-syntactic correspondent is taken to indicate the presence of semantic composition - meaning changing operations with no syntactic reflexes. Second, type-coercion has been formally treated as involving the insertion of an operator, suggesting a neatly packaged psychologically viable mechanism that could be subjected to experimental manipulation and 
testing. If the aspectual coercion hypothesis and the analysis that underlies it is on the right track, then some psychological and neurological correlates of the aspectual resolution are expected to be found.

Experimental research over the past decade, using a variety of tasks, has shown that the composition of measure adverbs with semelfactive and telic predicates does engender additional processing cost. Although this cost has hitherto been interpreted as the reflex of coercion operators, there are certain aspects of the phenomenon that do not cohere well with such an interpretation. The semantics literature also contains an alternative to the coercion-based analysis of for-adverbs: a quantificational analysis in which for-adverbs are treated as denoting universal quantifiers over (relevant) subparts of a larger interval or event (Dowty 1979; Moltmann 1991). Cases like (2b) and (3) with iterative readings fall out naturally from the semantics of distributivity on this sort of analysis and do not require resort to coercion operators.

The goal of this paper is to provide a new universal quantifier analysis of foradverbs that can explain the experimental evidence, in particular the main pattern of gradual rise and tail-off observed during sentence comprehension (discussed in $\S 2)$. Crucially, the analysis we propose, building on the notion of contextually determined temporal partitions (Deo 2009) and intermediate distributivity (Schwarzschild 1996; Champollion 2010), is not only in line with the more parsimonious operatorfree approach to semantic composition but is also capable of addressing a number of other challenges faced by previous such analyses.

The rest of the paper is organized as follows: In $\$ 2$, we discuss the broad findings of experimental work investigating the behavior of measure adverbs. $\S 3$ reviews earlier proposals for the quantificational analysis and the challenges that these proposals face. In $\S 4$, we present our own universal quantifier analysis and in $\S 5$, we provide an interpretation of the experimental evidence that is compatible with the analysis proposed.

A terminological note: For/until adverbs have been variably called measure adverbs or durative adverbs in the literature. We use the two terms interchangeably in this paper, using "durative" mainly in the context of experimental work, where this has been the standard expression.

\section{Measure adverbials and experimental evidence}

Over the past decade, a large body of evidence has accumulated showing both computational cost and functional localization for durative adverbials composed with semelfactive/telic predicates. Table 1 below summarizes the evidence. The sentences given from (5) to (9) are sample stimuli and illustrate the sorts of contrasts that have been tested in each study. 
Deo \& Piñango

\begin{tabular}{|c|c|c|c|c|}
\hline & Study/Task & Contrast & Observation & Interpretation of effect \\
\hline$\overline{1 .}$ & $\begin{array}{l}\text { Piñango et al 1999, 2006 } \\
\text { Cross-Modal Lexical } \\
\text { Decision (CMLD) }\end{array}$ & (5) & $\begin{array}{l}\text { Increased reaction time } \\
\text { for }(5 b) 300 \mathrm{~ms} \text { after } \\
\text { adverb but no difference } \\
\text { right at the adverb }\end{array}$ & $\begin{array}{l}\text { Processing cost induced by } \\
\text { "iterative meaning without } \\
\text { morphosyntactic support"" }\end{array}$ \\
\hline$\overline{2 .}$ & $\begin{array}{l}\text { Piñango \& Zurif 2001 } \\
\text { Focal Brain Lesion (Aphasia) } \\
\text { Question-Answer Task }\end{array}$ & (6) & $\begin{array}{l}\text { Wernicke's Aphasics } \\
\text { performed at chance } \\
\text { (guessed) for (6b); above } \\
\text { chance for (6a) Broca's } \\
\text { Aphasics above chance } \\
\text { for (6a) \& (6b) }\end{array}$ & $\begin{array}{l}\text { "Implementation of ITER } \\
\text { recruits Wernicke's area } \\
\text { (left posterior superior } \\
\text { temporal cortex)" }\end{array}$ \\
\hline $\bar{~} 3$. & $\begin{array}{l}\text { Todorova et al 2000 } \\
\text { Self-Paced Reading }\end{array}$ & (7) & $\begin{array}{l}\text { Increased reading time } \\
\text { at the temporal adverb } \\
\text { in (7a) vs. (7b) }\end{array}$ & $\begin{array}{l}\text { Cost attributed to } \\
\text { (a) "telic commitment" } \\
\text { or } \\
\text { (b) "repair via ITER insertion" }\end{array}$ \\
\hline$\overline{44 .}$ & $\begin{array}{l}\text { Downey 2006 } \\
\text { Event-Related Response } \\
\text { Potential (ERP) }\end{array}$ & (8) & $\begin{array}{l}\text { Sustained centro-parietal } \\
\text { positivity starting } \\
\text { at } 300 \mathrm{~ms} \text { after adverb }\end{array}$ & $\begin{array}{l}\text { Increased activity results } \\
\text { from "semantic generation } \\
\text { of iterative interpretation" }\end{array}$ \\
\hline 5. & $\begin{array}{l}\text { Brennan \& Pylkkänen } 2008 \\
\text { Self-Paced Reading } \\
\text { Magnetoencephalography } \\
\text { (MEG) }\end{array}$ & $\begin{array}{l}\text { (9) } \\
\text { (9) }\end{array}$ & $\begin{array}{l}\text { Increased reading time } \\
\text { at verb in }(9 a) \\
\text { Increased brain activity for } \\
\text { (9a) in the VMF around } \\
\text { the verb ( } 437-452 \mathrm{~ms})\end{array}$ & $\begin{array}{l}\text { Cost attributed to } \\
\text { (a) "repair via ITER" } \\
\text { or } \\
\text { (b) "pragmatic adjustment" }\end{array}$ \\
\hline
\end{tabular}

Table 1 Experimental findings for aspectual coercion

(5) Piñango et al 1999, 2006

a. The man examined the little bundle of fur for a long time to see if it was alive.

b. The man kicked the little bundle of fur for a long time to see if it was alive.

(6) Piñango \& Zurif 2001

a. The horse jumped over the fence yesterday. once or many times?

b. The horse jumped for an hour yesterday. once or many times? 
Measure Adverbs

\section{Todorova et al 2000}

a. Even though Howard sent a large check to his daughter for many years, she refused to accept his money.

b. Even though Howard sent large checks to his daughter for many years, she refused to accept his money.

(8) Downey 2006

a. The girl dove into the pool for a penny.

b. The girl dove into the pool for an hour.

\section{Brennan \& Pylkkänen 2008}

a. For forty-five seconds, the computer beeped in the busy lab.

b. After forty-five seconds, the computer beeped in the busy lab.

There are three main observations regarding the computation of measure adverbs that come out from these studies: First, durative adverbs (for, until) + semelfactives are associated with longer reaction times/inSwartcreased brain activity than durative adverbs (for, until) + activities. Second, durative adverbs (for, until) + telic predicates are associated with longer reading times than durative adverb (for, until) + atelic predicates. Finally, patients with brain lesions in Wernicke's area cannot compute the iterative meaning associated with durative adverbs (for, until) + semelfactives. These observations can be interpreted as follows: (a) the processing of durative adverbs with telic and semelfactive predicates engenders cost; (b) this cost has peak manifestation some time after licensing (rather than at licensing point); and (c) this cost is cortically localizable.

On a first consideration, these experimental findings converge with a "mismatch and repair/reanalyze" approach, in which arguments incompatible with the selectional restrictions of durative adverbs are rendered compatible by the insertion of coercion operators. This approach is reflected in the literature which posits invisible meaning-changing coercion operators (such as ITER) in the semantics, triggered by type or sortal conflict to facilitate composition (Pustejovsky 1995, Jackendoff 1997, de Swart 1998). A closely related alternative approach takes such coercion operators to belong to the pragmatic component, facilitating the contextual enrichment of context-independent compositionally built up meanings via operators contributing iterativity, habituality, imperfectivity etc. (Dölling 2003, Egg 2005). We submit here that the delayed and sustained nature of the observed effects cannot be easily reconciled with an explanation involving the detection of a mismatch and its resolution via the insertion of a meaning-changing operator. That is, although the experimental findings report processing cost and delay, this does not provide clear evidence for the sort of discrete "fix" invoked in the coercion-based explanation. 
What the evidence actually suggests is the slow emergence of some process in the brain that remains active for some time and then gradually tapers off.

Moreover, an observation that has remained in the background in the literature is that iterative readings for semelfactives tend to occur with higher frequency, a fact that might predict the conventionalization of the iterative interpretation (one can imagine an implementation in which a coercion operator such as ITER becomes a diacritic on semelfactive verbs). Such frequency-based conventionalization carries with it an implication of its own - lower processing cost during comprehension. What we observe instead is that the iterative interpretation is accompanied by some semantic process that must be implemented always regardless of the frequency of this interpretation. In other words, the process is impervious to usage and it takes some time to emerge and be resolved.

The selectional mismatch plus coercion operator explanation is not only underdetermined by the evidence, but also unable to account for the delayed and sustained nature of the processing cost. This leads us to ask if there is a way of approaching the meaning of durative adverbs (and specifically for-adverbs) that can both predict the nature of the increased processing cost as well as avoid the stipulativeness of the selectional mismatch analysis.

\section{3 for-adverbials}

Having examined the nature of experimental findings in the domain of measure adverbs, let us return to understanding the treatment of for-adverbs within semantics. The difference between the measure function analysis and the quantificational analysis essentially amounts to whether divisivity or atelicity (modulo coercion) is encoded as a requirement on the input to these functions (10) or whether it is derived as a consequence of encoding universal quantification as part of the meaning of for-adverbs (11).

$$
\begin{aligned}
& \llbracket \text { For x-time } \rrbracket=\lambda P_{\text {atelic }} \lambda e[\tau(e)=\mathrm{x} \text {-time } \wedge P(e)] \\
& \llbracket \text { For x-time } \rrbracket=\lambda P \lambda i\left[\mathrm{x} \text {-time }(i) \wedge \forall i^{\prime} \subset i \rightarrow P\left(i^{\prime}\right)\right]
\end{aligned}
$$

Despite the intuitive attractiveness of an analysis like (11) that does not stipulate divisive/atelic reference for its arguments, the universal quantifier analysis is not without challenges, wellknown and well discussed in the literature.

\subsection{The minimal parts problem}

Atelicity is most often construed in terms of the subinterval property. A predicate $P$ has the subinterval property if and only if whenever it holds of an interval, it also 
holds of each of its subintervals (Bennett \& Partee 1972; Dowty 1979). The universal quantifier treatment encodes the subinterval property directly into the truthconditional content of the for-adverb. Unrestricted universal quantification over parts of the measuring interval will obviously lead to too strong truth-conditions, since it will require the predicate to hold at every smallest subinterval (Dowty 1979, Moltmann 1991, Krifka 1998, Zucchi \& White 2001, van Geenhoven 2004, among others). It has been noted that even lexically atelic predicates may not necessarily have the subinterval property in this strong sense. For example, predicates like waltz denote events with a certain structure involving three steps: intervals which correspond to subparts of the runtime of minimal waltzing events only questionably qualify as intervals instantiating waltzing events. This indicates the need for a weakened construal of the subinterval property. Beyond the natural temporal lengths of events, there is the fact that short gaps in instantiation within the measuring interval are fully acceptable in the interpretation of for-adverbs. For instance, John jogged for an hour is judged true even if John takes a three minute break sometime in the middle to catch his breath and take a sip of water. An extreme instance of gap tolerance can be seen in the web-attested example in (12).

(12) The legend goes that Virgil wrote the Aeneid for ten years, no more than three lines each day. ${ }^{1}$

We run into a more serious and systematic version of the minimal parts problem when we consider the fact that, in addition to their single event 'continuous' readings, for-adverbs often have frequentative or iterative readings (Van Geenhoven 2004) in which the predicate is understood to have been instantiated several times within a measuring interval. The events must have occurred with some regularity and the gaps in instantiation may be quite significant. Some examples of the iterative use of for-adverbs are given in (13). van Geenhoven (2004) notes that these iterative readings are at least as systematic as the continuous ones but have been included only marginally as explananda in analyses of for-adverbs.

(13) a. John read the letter for an hour. (Krifka 1989: 93)

b. John found his son's tricycle in the driveway for six weeks. (Dowty 1979: 82)

c. Peter jogged for a year.

Moltmann (1991: 638-39), working within an event-based semantics, characterizes a weaker domain of quantification by appealing to a contextually determined 'relevant parthood' relation, labeled $P$. On her view:

1 http://www.clockrootbooks.com/excerpts/lunarsavingstimeexcerpt.html 
The part structure of an interval cannot be taken as being strictly divisive in a mathematical or physical sense. Rather, it appears that semantics involves a coarser part structure and a notion of relevant or contextually determined part, namely the relation P. Depending on the type of event, the part structure of the interval must have smallest subintervals of a certain minimal length... Therefore, the intended meaning of ' $\mathrm{P}$ ' is the relation 'is a relevant part of', a relation which does not involve any subinterval of the measuring interval... $\mathrm{P}$ has to be understood not as a part relation in a strict mereological sense, but rather as a contextually determined relation that may be coarser than the mereological part relation.

Moltmann's proposal brings out the context-dependent nature of the interpretation of for-adverbs and the need for employing a coarser-grained part structure in analyzing them. However, as she herself observes, the relation $P$ can be straightforwardly derived neither from the notion of subsets in set theory or from mereological assumptions about parthood. A solution to the minimal parts problem thus rests on a more explicitly formulated proposal about the contribution of context to for-adverb interpretation, such that both continuous and iterative readings can emerge.

\subsection{Restricted scopal interactions}

If for-adverbs are treated, à la Dowty and Moltmann, as denoting universal quantifiers over parts of the measuring entity, their scopal behavior is expected to be similar to their nominal and adverbial counterparts such as every and always. Foradverbs are expected to scope freely within their clauses. However, it has been noted that scopal interaction seems rather restricted and for-adverbs take narrow semantic scope with respect to quantifiers that they syntactically take scope over (Zucchi \& White 2001; van Geenhoven 2004; Kratzer 2007; Champollion 2010).

In brief, the facts (illustrated with singular indefinites) seem to be as follows: indefinites are obligatorily interpreted with wide scope with respect to for-adverbs (examples in (14b-d) are from Kratzer 2007. For instance, (14a) could possibly be understood as involving pushing events with different carts over the course of an hour. However, that reading is entirely unavailable, the only available reading being that a single cart was pushed during the hour-long interval.
a. John pushed a cart for an hour.
$\exists>\forall ; ? ? \forall>\exists$
b. I dialed a wrong phone number for five minutes.
$\exists>\forall ; ? ? \forall>\exists$
c. He kicked a wall for a couple of hours.
$\exists>\forall ; ? ? \forall>\exists$
d. I petted a rabbit for two hours.
$\exists>\forall ; ? ? \forall>\exists$ 
What is remarkable about this observation is that the narrow scope reading of indefinites cannot be made salient even if the wide scope reading results in pragmatic oddity. The sentences in (15) are not rescuable by construing an iterated occurrence of flea-finding or proof-discovering events over subparts of the measure interval, i.e. on the narrow scope reading of the indefinite NPs in the sentence.

a. ??John found a flea/two fleas/some fleas for an hour.

b. ??John noticed a discrepancy/three discrepancies for a week.

c. ??John discovered a new proof/two new proofs for a week.

A further observation is that the narrow scope reading is made available given appropriate contextual information that allows for the distribution of the indefinite over parts of the measuring entity. The example in (16a) is perfectly acceptable on the narrow scope reading, given the contextual information that medicinal pills are taken on a regular basis over an interval of time. In a context in which a bicycle designed for carrying three children at a time changes owners, thus carrying different triads of children at any given time, (16b) is fully acceptable.

a. The patient took a pill/two pills for a month. (from Champollion 2010)

$\forall>\exists ; ? \exists>\forall$

b. This bicycle carried three children around Amsterdam for twenty years. (from Rothstein 2004)

$\forall>\exists ; ? ? \exists>\forall$

c. John attended a Yoga class for three years.

$\forall>\exists ; \exists>\forall$

Moreover, the presence of adverbs that further specify the spatiotemporal location of events seems to have an effect on the acceptability of narrow scope readings for indefinites in the scope of for-adverbs. The examples in (17) illustrate this possibility.
a. Jane ate an egg/two eggs at breakfast for a month.
$\forall>\exists ; ? ? \exists>\forall$
b. We built a huge snowman in our front yard for many years. $\forall>\exists ; \exists>\forall$
c. The ex-convict carried two guns with him for five years.
$\forall>\exists ; \exists>\forall$
d. John pushed a dimsum cart around for many years.
$\forall>\exists ; \exists>\forall$

The availability of free scope for indefinites thus seems to largely depend on the presence of contextual information. This suggests that if quantification is involved in for-adverbs, it must be sensitive to some information retrievable from the context, in the absence of which wide scope is obligatory for indefinites. Any quantificational analysis of for-adverbs must therefore take this context-sensitivity into consideration in deriving the scopal behavior of for-adverbs. 


\section{Analysis}

The availability of continuous and iterative readings of predicates in composition with for-adverbs as well as the scopal behavior of for-adverbs is reminiscent of the profile of imperfective aspect. Imperfective aspect has also been associated with continuous (or event-in-progress) readings in which an interval lies within the runtime of some event instantiating a predicate $P$ and iterative (habitual/generic) readings which involve the regular instantiation of a predicate within some interval. Moreover, it has been observed that habitual/generic sentences containing indefinites often sound odd because these indefinites cannot receive a narrow scope interpretation (Carlson 1977, Krifka et al. 1995).
a. ??John eats an apple/smokes a cigarette.
b. ??John eats an egg/two eggs.
c. ??Mary drinks a beer.

We take these similarities between the imperfective and for-adverbs as indicative of a common semantic core and extend the analysis for the imperfective proposed in Deo 2009a, 2009b to for-adverbs in order to overcome the challenges for their quantificational analysis.

To anticipate the coming analysis, the claim is that for-adverbs contain a universal quantifier whose domain is a regular partition (i.e. a set of collectively exhaustive, non-overlapping, equimeasured subsets) of the measuring interval. The partition measure (the length of each partition member) is a free variable with a contextually determined value. The continuous and iterative readings involve the setting of the partition measure to variable values. The availability of narrow scoping for indefinites has to do with whether the sentential or extrasentential context allows for a precise determination of the partition measure.

\subsection{Setup}

We assume as our basic ontology a non-null domain of intervals $\mathscr{I}$ and a domain of events $\mathscr{E} . \tau$ is a function from $\mathscr{E}$ to $\mathscr{I}$ assigning to each $e \in \mathscr{E}$ a runtime $i \in \mathscr{I}$. Sentence radicals are predicates of eventualities (eventive or stative) arising from lexical predicates with their individual (non-eventuality) arguments saturated. We assume that aspectual operators like for-adverbs and in-adverbs may either apply to predicates of eventualities denoted by sentence radicals or to predicates of intervals returned by other aspectual modifiers. The instantiation of a predicate $P$ (over eventualities or intervals) at an interval $i$ is defined in terms of the coINcidence relation in (19). 
Measure Adverbs

$$
\operatorname{COIN}(P, i)= \begin{cases}\exists e[P(e) \wedge \tau(e) \circ i] & \text { if } P \subseteq \mathscr{E} \\ P(i) & \text { if } P \subseteq \mathscr{I}\end{cases}
$$

For any $i \in \mathscr{I}$, a regular partition of $i-\mathscr{R}_{i}-$ is the set of non-empty collectively exhaustive, mutually exclusive, equimeasured subsets of $i$. For any $\mathscr{R}_{i}$, each of its subsets will have the same measure - the partition measure.

$\mathscr{R}_{i}$ is a regular partition of $i$ if $\mathscr{R}_{i}$ is a set of intervals $\{j, k \ldots n\}$ such that

a. $\bigcup\{j, k \ldots n\}=i$ collectively exhaustive

b. $\forall j, k \in \mathscr{R}_{i} \rightarrow j \cap k=\emptyset$ if $j \neq k$ mutually exclusive

c. $\forall j, k \in \mathscr{R}_{i} \rightarrow \mu(j)=\mu(k)$

(where $\mu(x)$ stands for the Lebesgue measure of $x$ ). ${ }^{2} \quad$ equimeasured

\subsection{Proposal}

For-adverbs denote part quantifiers over a contextually determined regular partition of the measuring interval. This means that the partition measure (the length of each cell of the partition) is a free variable whose value is anaphoric on the context. A sentence of the form "for x-time (P)" is true at an interval $i$ iff the duration of $i$ is $\mathrm{x}$-time and every member $j$ of a contextually determined regular partition of $i, \mathscr{R}_{i}{ }^{c}$, COINcides with $P$.

$$
\llbracket \text { for x-time } \rrbracket=\lambda P \lambda i\left[\operatorname{time}(i)=x \wedge \forall j\left[j \in \mathscr{R}_{i}{ }^{c} \rightarrow \operatorname{COIN}(P, j)\right]\right]
$$

Taking the restriction to be a contextually determined regular partition allows for a weaker but set-theoretically well-defined construal of the part structure involved in for-adverbs. Moltmann's insight about the context dependence of the 'part of' relation is incorporated by making the partition-measure anaphoric on context.

\subsubsection{Continuous and iterative readings}

This treatment gives a straightforward account of the 'continuous' and 'iterative' readings of for-adverbs. The continuous reading arises when the partition measure is set to some value among the infinitesimals. For any interval $i, \mathscr{R}_{i}$ inf is a set of subsets of $j$ of infinitesimal value. A step-by-step derivation of (22a) is given in (22b-d).

a. John walked for an hour.

2 The Lebesgue measure is a method of assigning length, area, or volume to subsets of Euclidean space. Intervals are a proper subset of the Lebesgue-measurable subsets of the real number line. 
b. $\llbracket$ for an hour $\rrbracket=\lambda P \lambda i\left[\operatorname{time}(i)=1\right.$ hour $\left.\wedge \forall j\left[j \in \mathscr{R}_{i}{ }^{\text {inf }} \rightarrow \operatorname{COIN}(P, j)\right]\right]$

c. $\llbracket \mathrm{John}$ walk $\rrbracket=\lambda e[\operatorname{walk}(e) \wedge \operatorname{ag}(e, \mathrm{John})]$

d. $\llbracket$ for an hour $($ John walk $) \rrbracket=\lambda P \lambda i\left[\operatorname{time}(i)=1\right.$ hour $\wedge \forall j\left[j \in \mathscr{R}_{i} \inf \rightarrow\right.$ $\operatorname{COIN}(P, j)]](\lambda e[\operatorname{walk}(e) \wedge \operatorname{ag}(e, \operatorname{John})])$

$=\lambda i\left[\operatorname{time}(i)=1\right.$ hour $\wedge \forall j\left[j \in \mathscr{R}_{i}{ }^{\text {inf }} \rightarrow \exists e[\operatorname{walk}(e) \wedge \operatorname{ag}(e, J o h n) \wedge \tau(e) \circ\right.$ $j]]]$

The predicate John walk for an hour is true at an interval $i$ iff the duration of $i$ is an hour and every cell $j \in \mathscr{R}_{i}{ }^{\text {inf }}$ COINcides with an event $e$ of John walking. If every subset $j \in \mathscr{R}_{i}{ }^{\text {inf }}$ COINcides with an event of John walking, it follows that $i$ itself COINcides with an event of John walking. The continuous or durative reading with for-adverbs is thus one that arises on a particular construal of the partition measure.

The iterative reading arises when the partition measure must be set to a noninfinitesimal value. Retrieving this value depends on information coming from the predicate's temporal structure, the absolute length of the measure interval, and sentential as well as extra-sentential context. The iterative inference comes from partitioning the for-interval into relatively small-sized cells: the partition measure that makes sneeze for an hour true may have a larger value than a partition measure that makes jump for an hour true. Similarly, atelic predicates like jog, and swim are also interpreted iteratively, as being instantiated regularly across the measuring interval, when the measuring interval is large relative to typical jogging or swimming events.

a. John jumped/sneezed/coughed/kicked a wall for an hour.

b. John jogged/ran/swam for a year.

\subsubsection{For-adverbs and telic predicates}

Nothing in the formulation that we give here leads to an expectation that predicates lacking the subinterval property are unacceptable arguments to for-adverbs. That is, unlike the measure function approach that restricts the domain of application of foradverbs to atelic predicates, this analysis involves no selectional restrictions. Telic predicates compose directly with for-adverbs and are expected to be ruled out only by pragmatic considerations. This seems to be the right approach to understanding the asymmetry in the acceptability of telic and atelic predicates in the scope of foradverbs. As the examples in (24) show, telic predicates are perfectly acceptable with for-adverbs and give rise to iterative readings (24a-b) in some cases and ongoing event readings in others $(24 \mathrm{c})$.

a. Mary played a sonata/walked a mile/swam two miles for two months. 
Measure Adverbs

b. John biked to Whole Foods/drove to the university for a year.

c. John read a book/built a sand castle/baked a cake for an hour.

On our analysis, the acceptability of the examples in (24) follows from the possibility of interpreting predicates like play a sonata and walk a mile as being instantiated at regular intervals across the measuring interval, with possible variability in the precise granularity (size of partition measure). Playing a sonata for two months may involve weekly practicing events, while regular walking may occur more than a few times a week. Regardless, the interpretation of these predicates does not involve the insertion of coercion operators such as ITER as has been proposed in the literature, but rather depends on the contextual access to a measure that allows the partitioning of the measuring interval along which the event predicate distributes. When the absolute length of the measuring interval is large in comparison to the duration of a "typical" event in the predicate, the partition measure is assumed to be correspondingly large. Iterative readings with for-adverbs do not depend on the (a)telicity of the argument, but rather on the interaction between the duration of events, the length of the measuring interval, and context. We provide a sample derivation for (24b) in (25).

a. John biked to Whole Foods for three years.

b. $\llbracket$ for three years $\rrbracket=\lambda P \lambda i\left[\operatorname{time}(i)=3\right.$ years $\left.\wedge \forall j\left[j \in \mathscr{R}_{i}{ }^{c} \rightarrow \operatorname{COIN}(P, j)\right]\right]$

c. $\llbracket \operatorname{John}$ bike to Whole Foods $\rrbracket=\lambda e[\operatorname{bike}(e) \wedge \operatorname{ag}(e, \operatorname{John}) \wedge \operatorname{th}(e$, Whole Foods $)]$

d. $\llbracket$ for three years $($ John bike to Whole Foods $) \rrbracket=\lambda P \lambda i[$ time $(i)=3$ years $\wedge$ $\left.\forall j\left[j \in \mathscr{R}_{i}{ }^{c} \rightarrow \exists e[P(e) \wedge \tau(e) \circ j]\right]\right](\lambda e[\operatorname{bike}(e) \wedge \operatorname{ag}(e, \operatorname{John}) \wedge \operatorname{th}(e$, WholeFoods $)])$

$=\lambda i\left[\operatorname{time}(i)=3\right.$ years $\wedge \forall j\left[j \in \mathscr{R}_{i}{ }^{c} \rightarrow \exists e[\operatorname{bike}(e) \wedge \operatorname{ag}(e, \operatorname{John}) \wedge\right.$ $\operatorname{th}(e$, Whole Foods $) \wedge \tau(e) \circ j]]]$

Finally, there is no "imperfective coercion" involved in the derivation of (24c). The ongoing event reading simply follows from regular composition assuming an infinitesimal partition measure.

\subsubsection{Scopal restrictions}

Recall from $\$ 3.2$ the main observation with regard to the restricted scopal interactions observed with for-adverbs. Quantified NPs (indefinites) receive obligatory wide scope when in the syntactic scope of for-adverbs (26a), unless sentential and extra-sentential contextual information supports a narrow scope reading (26b-c).

a. John pushed a cart for an hour. $\quad \exists>\forall ; ? ? \forall>\exists$

b. We built a huge snowman in our front yard for many years. $\forall>\exists ; ? ? \exists>\forall$ 
c. The patient took a pill/two pills for a month. (from Champollion 2010)

$$
\forall>\exists ; ? \exists>\forall
$$

We suggest, building on recent and earlier work, that this resistance to narrow scoping for indefinites in the absence of supporting context is a feature characterizing quantification involving non-atomic domains more generally (Schwarzschild 1996; Champollion 2010a, 2010b). The idea originates in work by Gillon (1987; 1990) and is discussed in detail in Schwarzschild 1996:§5. Consider a sentence like (27), from Gillon 1987, where the men denotes Rodgers, Hammerstein, and Hart. ${ }^{3}$

The men wrote musicals.

The sentence is judged true, although it emerges false on both a collective and a distributive construal. The predicate wrote musicals in this case cannot be interpreted as applying to the three men collectively (since they did not write any musical together) nor can it be interpreted distributively (since none of them wrote a musical by themselves). In order to account for the truth of the sentence, we must admit yet another interpretation: the predicate wrote musicals must apply to nonatomic parts of the subject denotation. The availability of such readings, called intermediate readings, has led to 'cover-based' analyses in which distribution of a predicate involves universal quantification over subsets, rather than atomic members, of the plural individual denoted by the subject (Gillon 1987, 1990; Schwarzschild 1996). ${ }^{4}$ The mere existence of a cover is not enough to guarantee the availability of intermediate readings. What is required is the existence of contexts that make specific covers pragmatically salient. Crucial to the asymmetry in distributive vs. intermediate construal is the free availability of atomic parts for distribution and the context-dependent availability of non-atomic parts.

On the analysis we provide, for-adverbs contain quantifiers over a regular partition - a set of nonatomic entities of unspecified size (made determinate only by contextual information). We suggest that within a non-atomic domain such as time, the closest counterpart to atom-level distributivity is distributivity over an infinitesimal partition. An infinitesimal measure is the closest to a "pure atom" in the domain of atomic objects (such as count individuals or events). This makes such a partition always salient and for-adverbs tend to be interpreted with respect to such a partition, explaining the preference for "continuous" interpretations of for-modified predicates. In the non-infinitesimal case, the value of the restriction depends on the contextually given partition measure. Narrow scope readings for indefinites in the syntactic scope of for-adverbs are only possible when the context makes the

3 The facts are that Rodgers and Hammerstein wrote Oklahoma together, and Rodgers and Hart wrote On your Toes together (Champollion 2010b: 170).

4 A cover $C$ of some set $P$ is defined as a set of nonempty subsets of $P$ whose union is $P$. 
partition measure sufficiently salient. ${ }^{5}$

The scopal facts are now accounted for in the following way: wide scope for indefinites is obligatory when the partition measure has value among the infinitesimals. This is the continuous reading, involving reference to a single event overlapping with all cells in an infinitesimal partition of the measure interval. In this case, wide scope follows from uniqueness of participants (Krifka 1998), defined in (28).

$$
\forall x, y \in U_{P} \forall e \in U_{E}[\theta(x, e) \wedge \theta(y, e) \rightarrow x=y]
$$

Narrow scope is possible only when the partition measure assumes a contextuallydetermined non-infinitesimal value. A non-infinitesimal partition measure yields the iterative reading which involves reference to distinct events overlapping with each cell of a regular partition. When the partition measure cannot be determined precisely from the sentential/extra-sentential context, the restriction remains vague and the wide scope reading emerges. This leads to pragmatic oddity with predicates involving consumed/effected/totally affected arguments (29b) as well as with achievements like find (29a). With other predicates, the wide scope reading is perfectly acceptable (30).

(29) a. ?? John found/discovered/noticed a flea for an hour.

b. ?? John killed a flea/ate an apple/baked a cake for a month.

(30) John washed a car/babysat two children/dialled a phone number for a month.

Any information that facilitates a precise determination of the partition measure also serves to make salient the narrow scope reading. Consider here, in addition to the examples in (17) and (18), the examples in (31). In these cases, the temporal adverb, prepositional phrase, or the functional nature of the object denotation serve to make precise a partition measure, allowing for the narrow scope reading to emerge.
a. John killed a rabbit after dinner for a month.
b. John found a note in his lunch box for a week.
c. John tore up his paycheck for three years.

\section{A psycholinguistic implementation}

Having presented our analysis we are now in a position to come back to the psycholinguistic pattern observed and see how the cost can be understood in light of

5 Champollion (2010a, 2010b) originally brings this insight from the literature on distributivity to the understanding of aspect and for-adverbs. His construal of the meaning of for-adverbs as involving "stratified distributive reference" is close in spirit to ours even though he takes distributive reference to be a presupposition rather than part of the asserted meaning of for-adverbs. 
it. Our analysis places no selectional restrictions on the arguments of for-adverbs. It makes no appeal to coercion operators that type-shift mismatching arguments to iterative or imperfective predicates. The observation that for-adverbs select for divisive predicates and reject (uncoerced) non-divisive predicates is an epiphenomenal effect of the restricted and heavily context-dependent availability of distributive construals of predicates in the scope of these expressions, not a direct effect of hard-wired selectional restrictions that are violated by non-divisive arguments.

So if the cost observed can no longer be attributed to the introduction of typeshifting operators as a mismatch-repair mechanism, where does it come from? We believe that this cost reflects the process of retrieving a partition measure from the context. The semantics-pragmatics interaction in this case is very clearly circumscribed to identifying the temporal granularity at which the predicate is distributed along the measuring interval. The retrieval of this information is necessary in all contexts except those in which an infinitesimal partition is appropriate. That is, any iterative interpretation will involve the retrieval of a partition measure, including one involving divisive predicates composed with relatively longer measure intervals, such as the examples in (32b-c). Any such retrieval is expected to be associated with processing cost.

a. John jumped for an hour.

b. John jogged for a year.

c. John slept in the attic for six months.

Thus, this analysis accounts for the delayed and sustained profile of the psycholinguistic effect: it involves no meaning-changing operations but the mining of lexical and extra-lexical context for the retrieval of appropriate information required so that the semelfactive + for-adverb segment can be fully interpreted. This process implies computation that is extra-syntactic (source of the cost), that takes some time to fully develop (processing delay) and that, depending on the source of information about the partition measure, may take some time to disappear (sustained).

\section{References}

Bennett, Michael \& Barbara H. Partee. 1978. Toward the Logic of Tense and Aspect in English. Reproduced by Indian University Linguistics Club.

Bott, Oliver. 2008. Doing it again and again may be difficult, but it depends on what you are doing. In Natasha Abner \& Jason Bishop (eds.), Proceedings of WCCFL 27, 63-71. Somerville MA: Cascadilla.

Brennan, James \& Liina Pylkkanen. 2008. Processing events: Behavioral and neuromagnetic correlates of aspectual coercion. Brain and Language 106(2). 132143. 
Carlson, Gregory. 1977. Reference to Kinds in English: University of Massachusetts dissertation.

Champollion, Lucas. 2010a. for-adverbials and the specified quantity generalization. Handout of talk presented at the 34th Penn Linguistics Colloquium.

Champollion, Lucas. 2010b. Parts of a whole: Distributivity as a bridge between aspect and measurement: University of Pennsylvania dissertation.

Deo, Ashwini. 2009a. Imperfective readings: partitions as quantificational domains. In Ed Cormany, Satoshi Ito \& David Lutz (eds.), Proceedings of SALT 19, OSU, 109-123. Ithaca, NY: Cornell University Press.

Deo, Ashwini. 2009b. Unifying the imperfective and the progressive: partitions as quantificational domains. Linguistics \& Philosophy 32(5). 475-521.

Dölling, Johannes. 2003. Flexibility in adverbial modification: Reinterpretation as contextual enrichment. In E. Lang, C. Maienborn \& C. Fabricius-Hansen (eds.), Modifying Adjuncts, Berlin: Mouton de Gruyter.

Downey, Ryan Andrew. 2006. Examination of lexical properties during auditory sentence processing using event-related potentials: University of California, San Diego and San Diego State University dissertation.

Dowty, David. 1979. Word Meaning and Montague Grammar. Dordrecht: Kluver Academic Publishers.

Egg, Marcus. 2005. Flexible semantics for reinterpretation phenomena. Stanford: CSLI.

Gillon, Brendan. 1987. The readings of plural noun phrases in english. Linguistics and Philosophy 10. 199-219.

Gillon, Brendan. 1990. Plural noun phrases and their readings: A reply to Lasersohn. Linguistics and Philosophy 13. 477-485.

Jackendoff, Ray. 1997. The architecture of the language faculty. The MIT Press.

Kratzer, Angelika. 2008. On the plurality of verbs. In Johannes Dölling and Tatjana Heyde-Zybatow and Martin Schäfer (ed.), Event structures in linguistic form and interpretation, 269-300. Berlin: Mouton de Gruyter.

Krifka, Manfred. 1989. Nominal reference, temporal constitution, and quantification in event semantics. In R. Bartsch, J. van Benthem \& P. van Emde Boas (eds.), Semantics and contextual expressions, 75-115. Dordrecht: Foris.

Krifka, Manfred. 1992. Thematic relations as links between nominal reference and temporal constitution. In Ivan Sag \& Anna Szabolcsi (eds.), Lexical Matters, 29-53. Stanford: CSLI Publications.

Krifka, Manfred. 1998. The origins of telicity. In Susan Rothstein (ed.), Events and grammar, 197-235. Dordrecht: Kluwer.

Krifka, Manfred, Francis J. Pelletier, Greg Carlson, Alice ter Meulen, Gennaro Chierchia \& Godehard Link. 1995. Genericity: An Introduction. In The Generic Book, 1-124. Chicago: The University of Chicago Press. 
Moens, Marc \& Mark Steedman. 1988. Temporal ontology and temporal reference. Computational Linguistics 14(2). 15-28.

Moltmann, Friederike. 1991. Measure adverbials. Linguistics and Philosophy 14. 629-660.

Pickering, Martin, Brian McElree, Steven Frisson, Lillian Chen \& Matthew Traxler. 2006. Underspecification and aspectual coercion. Discourse Processes 42(2). 131-155.

Piñango, Maria, Aaron Winnick, Rashad Ullah \& Edgar Zurif. 2006. Time-course of semantic composition: The case of aspectual coercion. Journal of psycholinguistic research 35(3). 233-244.

Piñango, Maria \& Edgar Zurif. 2001. Semantic operations in aphasic comprehension: implications for the cortical organization of language. Brain and Language 79(2). 297-308.

Piñango, Maria, Edgar Zurif \& Ray Jackendoff. 1999. Real-time processing implications of enriched composition at the syntax-semantics interface. Journal of Psycholinguistic Research 28(4). 395-414.

Pustejovsky, James. 1995. The generative lexicon. The MIT Press.

Rothstein, Susan. 2004. Structuring events. Oxford: Blackwell.

Schwarzschild, Roger. 1996. Pluralities, vol. 61. Springer.

de Swart, Henriette. 1998. Aspect Shift and Coercion. Natural Language and Linguistic Theory 16. 347-385.

Todorova, Marina, Karen Straub, William Badecker \& Robert Frank. 2000. Aspectual coercion and the online computation of sentential aspect. In Proceedings of the twenty-second annual conference of the cognitive science society, Philadelphia, PA, 3-8.

van Geenhoven, Veerle. 2004. For-adverbials, frequentative aspect, and pluractionality. Natural Language Semantics 12(2). 135-190.

Zucchi, Sandro \& Michael White. 2001. Twigs, Sequences and the Temporal Constitution of Predicates. Linguistics and Philosophy 24(2). 223-270.

Ashwini Deo

Linguistics, Yale University

370, Temple Street

New Haven, CT-06520

ashwini.deo@yale.edu
Maria Piñango

Linguistics, Yale University

370, Temple Street

New Haven, CT-06520

maria.pinango@yale.edu 